\title{
THE EFFECT OF THE SAFETY STOCK ON THE OCCURRENCE PROBABILITY OF THE STOCK SHORTAGE
}

\author{
János Korponai ${ }^{1}$, Ágota Bányainé Tóth ${ }^{2}$, Béla Illés ${ }^{2}$ \\ ${ }^{1}$ University of Miskolc, József Hatvany Doctoral School for Information Science, Hungary \\ ${ }^{2}$ University of Miskolc, Institute of Logistics, Hungary \\ Corresponding author: \\ János Korponai \\ University of Miskolc \\ József Hatvany Doctoral School for Information Science \\ H-3515 Miskolc-Egyetemváros, Hungary \\ phone: (+36) 30-525-4645 \\ e-mail: janos.korponai@gmail.com
}

Received: 14 October 2016

Accepted: 23 January 2017

\begin{abstract}
The objective of the logistics management is to guarantee the stock level required for the adequate handling of production at the lowest possible level of costs and risks. The main purpose of the paper is to present the relations between stock level and risk of shortages. As a result of the research, the introduction of the safety stock is the solution to cover the effects of the uncertain factors in the supply chain. The theoretical approach of the model assumes a deterministic operational environment, in practice, however, there are several unpredictable factors influencing the operation of the production company. By using the periodic and continuous review models, the paper presents the effects of demand changes and stochastic length of replenishment time on the risk of stock availability. We need to quantify a service level which determines the accepted probability of the shortage occurrence.

KEYWORDS

demand changes, safety stock, service level, shortage, stochastic, supply accuracy.
\end{abstract}

\section{Introduction}

It often happens in practical logistics that the actual utilisation demand cannot be satisfied immediately. The continuity of service, in some cases, is broken by a disturbance in a stage of the supply chain, which causes a significant confusion for both the customer and the supplier. In other cases, the reason is a planned stock management strategy that can be led back to a certain aspect of economic efficiency.

The classical stockpile management approaches the optimisation of the stock level from the side of expenses, meaning that the optimal stock level is represented by the stock derived from the lowest total costs. Among the costs of the stockpile management system, we differentiate three basic cost categories:

- cost elements related to the procurement activity,

- costs related to stock holding,

- costs related to stock shortage consequences.

These three cost groups can be modified to the detriment of one another $[1,2]$. The holding costs in- crease linearly with the increase of the lot size, while the costs related to procurement decrease with the increase of the order quantity [3]. Similarly, the holding costs are in a trade-off relation with the costs of stock shortage. The task is the definition of the optimum of the total costs function that fulfils the cost-minimising target, and the quantification of the derivable order quantity and of the order period [4].

\section{Literature review}

The first scientific model about an optimal lot size determination was published by Harris in 1913 in the article "How many parts to make at once" [5]. This model defines the production quantity optimisation with not acceptable stock-out periods and assumes deterministic conditions. Several extensions of the basic Economic Order Quantity model have been defined since that, describing the real operational processes in more detail, and giving answers to practical issues. 
In case of deterministic inputs, the model is extended with the analyses of the deterioration of goods [6], the quantity discounts [3], limited supplier capacity, the dynamic version of the economic lot size [7], etc., and several researches have also been done in the direction of stochastic factors such as demand fluctuation, lead time variation, fraction of the defective items [8] or shortages, using a probability density function, etc.

The initial assumption of Harris's basic model that shortages are not allowed is too restrictive in a real industrial working environment. Park [9], Hollier and Mak [10], Grubbström and Erdem [11] assume that during shortage periods, all demand is either backlogged or lost. Deb and Chaudhuri extended the economic order quantity model by including completely back-ordered shortages [12]. They defined a replenishment policy where the inventory cycles were divided into two periods: in the first one, the demand was covered by inventory, while in the second part of the cycle, it was followed by a period of shortages. In their model, shortages were allowed in all cycles except for the final one. Also, Dave worked out a heuristic inventory-replenishment model with planned shortages and linearly increasing demand [13]. Teng and Yang considered a partial backlogging rate during the stock-out periods when the demand and cost fluctuate with time [14]. Many researchers extended the planned shortage model by considering varying shortage cost values [15] and assuming deteriorating items with imperfect quality [16-18].

\section{Research methods}

By walking around the initial conditions of the economic order quantity model, we analyse the effect of the changes of single parameters on the inventories, costs and the service level. The theoretical approach of the model assumes a deterministic operational environment. In practice, however, there are several unpredictable factors influencing the operation of the production company. By using the periodic and continuous review models, the paper presents the effects of demand changes and the stochastic length of replenishment time on the risk of stock availability.

We make the examination of the contexts by applying the ceteris paribus principle; we change only one parameter from among the initial conditions at once. The main purpose of our analysis, that by taking the changes of the time and the quantitative factors into consideration to define the level of the necessary safety stock, with which we may guaran- tee the service of the customer and the production on a predefined service level.

\section{Determination of the economic order quantity in case of planned shortage}

As in practice the demands are predictable with full certainty in exceptional cases only, and the decision between the higher inventory level and the risk of a stock-out situation is often of strategic importance, we use the probabilistic model with planned shortages in our analyses.

As an initial condition, we define that the unsatisfied demand due to stock shortage can be rescheduled by a defined cost level, and it will be fully performed at a later date [19]. The main questions of stock management models are the optimum quantity that can be procured on one occasion by the most favourable total costs, and the optimal scheduling of procurement. The balance between the stock level and the costs can be defined with the economic order quantity with planned shortage model, the initial conditions of which are as follow [1, 2, 4, 19-22]:

- The supply rate can be considered as being infinite, the stock replenishment is immediate, and so the replenishment time equals zero.

- The ordered quantity arrives as one item; frequency of supplies is scheduled for identical periods.

- The demand is known and pre-definable with absolute certainty.

- Both the customer and the supplier want to satisfy the demand. The demand is continuous, and the utilisation has a consistent intensity; thus, the demand rate is constant. Accordingly, within a supply period, the stock level shows a strictly monotonous descending linear function in relation to time.

- The stock shortage is accepted at a certain cost.

- The ordering costs are independent of the order quantity.

- The holding costs per unit are constant, and they change linearly with the stock quantity.

- By assuming an infinite time horizon, the costs are independent of the time factor.

- The purchase price per unit does not depend on quantity; thus, the purchase price does not influence the stock management policy to be chosen $[23,24]$.

In case of a constant utilisation demand with continuous and uniform intensity (Fig. 1a), and a procurement cycle with uniform period intervals, if the opening stock $d$ of the period $t$ is smaller than the total utilisation demand $q$ during the period, the stocks before the next period will decrease to zero at a certain $t_{0}$ point of time, followed by a stock shortage pe- 
riod with a $t_{2}$ length, at the end of which the stocks will be replenished. During period $t_{2}$, the continuous demand will lead to a backlog of $s$ level.

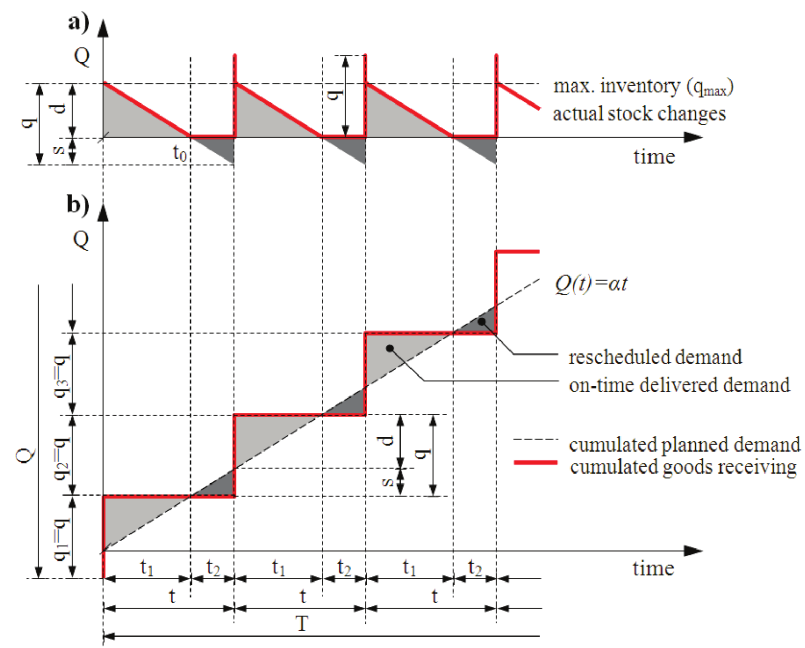

Fig. 1. Optimal stock level in case of regular stock replenishment and demand with uniform intensity with periods of stock shortage.

Figure 1b summarises in one diagram the arrival of stocks and the development of demands in relation to time, as a cumulated value. The difference between these two values shows the relation between the demands satisfied on time and the demands that are rescheduled.

The purchase costs incurring during the whole analysed period can be defined by multiplying the one-off purchase cost by the frequency of procurements [25]:

$$
C_{o}=\frac{Q}{q} \cdot c_{o}
$$

where $C_{o}$ - total purchase cost for the examined period, $Q$ - total purchase demand for the examined period, $q$ - purchase demand for a single period, economic order quantity, $c_{o}$ - cost of a single purchase order.

The holding costs can be defined as the area of sections due to the $t_{1}$ period of the sawtooth diagram [25]:

$$
C_{h}=\frac{1}{2} \cdot d \cdot t_{1} \cdot \frac{Q}{q} \cdot c_{h}=\frac{1}{2} \cdot d^{2} \cdot \frac{T}{q} \cdot c_{h}=\frac{d^{2}}{2 \cdot q} \cdot v \cdot r,
$$

where $C_{h}$ - total holding cost for the examined period, $d$ - the portion of the demand covered by stock within one single period, $t_{1}$ - period, during the demand is performed without delay at the time of its occurrence, $c_{h}$ - holding cost per time unit, $T$ - the length of the complete period, $v$ - purchasing price per unit, $r$ - annual holding cost rate.
During the quantification of the stock shortage costs, we must start from the relation that the continuous demand increases the level of the backlog, which can be expressed as the area of sections due to period $t_{2}$ of the sawtooth diagram $[20,25]$ :

$$
\begin{gathered}
C_{s}=\frac{1}{2} \cdot\left(q-d . t_{2} \cdot \frac{Q}{q} \cdot c_{s}\right. \\
=\frac{(q-d)^{2}}{2 \cdot q} \cdot T \cdot c_{3}=\frac{s^{2}}{s \cdot q} \cdot T \cdot c_{s},
\end{gathered}
$$

where $C_{s}$ - the shortage cost during the whole analysed period, $t_{2}$ - period, during the demands due must be rescheduled for a later date, $c_{s}$ - shortage cost per time unit.

The basic model of the economic order quantity starts from the relation that the purchase cost, the holding cost changes and the stock level change according to the order quantity. Accordingly, the more rarely orders are made, the more favourable the purchase costs are per unit, and at the same time, the holding costs are linearly increasing [26, 27]. The function of total costs can be defined as the sum of these three costs and the value of the purchased parts. The objective function is defining the minimum of the function of total costs $[2,4,20,23-25]$ :

$$
\begin{aligned}
& C(q ; d)=Q \cdot v+c_{o}+C_{h}+C_{s}=\frac{Q}{q} \cdot c_{o} \\
& +\frac{d^{2}}{2 \cdot q} \cdot T \cdot c_{h}+\frac{(q-d)^{2}}{2 \cdot q} \cdot T \cdot c_{s} \rightarrow \mathrm{min},
\end{aligned}
$$

where $C$ - total cost of inventory management for the examined period.

The optimal order quantity can be defined by solving the system of previous equations, where the form of partial derivatives according to $q$ and $d$ of the function of total costs is set equal to zero $[19,20$, 25, 28-30]:

$$
q=d \cdot \frac{c_{h}+c_{s}}{c_{s}}=\sqrt{\frac{2 \cdot Q}{T} \cdot \frac{c_{o}}{c_{h}}} \cdot \sqrt{\frac{c_{h}+c_{s}}{c_{s}}} .
$$

The on-time delivered quantity can be calculated as followed:

$$
d=\sqrt{\frac{2 \cdot Q}{T} \cdot \frac{c_{o}}{c_{h}}} \cdot \sqrt{\frac{c_{s}}{c_{h}+c_{s}}} .
$$

The optimal amount to be back-ordered [23]:

$$
s=q-d=q \cdot \frac{c_{h}}{c_{h}+c_{s}}=\sqrt{\frac{2 \cdot Q}{T} \cdot \frac{c_{o}}{c_{s}}} \cdot \sqrt{\frac{c_{h}}{c_{h}+c_{s}}} .
$$

The minimum total cost incurring during the whole period together with the money spent on purchased stocks:

$$
C=\sqrt{2 \cdot Q \cdot T \cdot c_{o} \cdot c_{h} \cdot \frac{c_{s}}{c_{h}+c_{s}}}+Q \cdot v
$$




\section{Factors influencing the deterministic operation}

Our theories applied in the case of the economic order quantity are influenced by the fact that the customer demands are not completely known, and disturbances can occur in our processes that together create uncertainty regarding the intensity of demands for purchased parts and the development of the stock level.

In practice, several unexpected events can lead to a shortage of stocks, e.g. excess usage due to a reject occurred for any reason within the production process, stock deviation, late delivery due to traffic obstacles, stocks with inappropriate quantity or quality, etc. These factors can be classified into two main groups.

The first group of factors includes uncertainties related to time, the occurrence of these events affects the availability of stocks in time. The other group of factors includes quality-related impacts, the occurrence of which causes a stock level modification of an unanticipated extent [23].

The impacts in both factor groups can have two directions. This means that in the case of the time factor, supplies ahead of schedule can happen along with delays in delivery, and in the case of quantitative factors, along with an unexpected excess usage, the stock discovered during an inventory can lead to the increase of the stock level. Accordingly, the challenges for some of the impacts are the management of the stock shortage and its consequence, and for impacts with the opposite direction, the challenges are the consequences related to the increased stock level.

Along the two groups of factors, we present the context related to the avoidance of stock shortage and the method of decreasing the occurrence level of the stock shortage to an acceptable level.

\section{Stock management mechanism of a stochastic operation environment}

Stock-outs can be caused any time by the factors such as fluctuating customer demand and variability in lead times for purchased materials or manufactured parts as well as by unexpected issues in the supply chain processes. To cover the effect of the unexpected factors, the inventory level must be adjusted accordingly with additional safety stock. The safety stock is not intended to eliminate all stock-outs fully but only a predetermined percentage. This service level means the desired probability that a stockout will not occur between the time an order is placed and the ordered quantity is received. The fulfilment of a higher service level requires significantly more safety stock, but in parallel, it would result in fewer stock-outs. The higher the safety stock is, the more the inventory holding costs are, and also the higher customer satisfaction can be reached. We must balance this trade-off between inventory costs and customer service $[23,24]$.

During the definition of our supply management strategy, we can choose from two basic models. Thus, we must separate the continuous and periodic review systems. In the case of a continuous review, the order quantity is constant; thus, the uncertainty affects the level of the closing stock at the end of the periods; while in the case of a periodic review, there are fixed times between the orders; thus, the uncertainty affects the order quantity. Both models are closely related to the Economic Order Quantity model with planned shortages. Although the demand or the lead time is not predictable, as an approximation of the best order quantity in practice we can use the formulas of the Economic Order Quantity model, and calculate the additional safety stock to cover the risk of shortages. By using the methods and equations, we can calculate the safety stock levels to achieve the targeted customer service levels [31].

\section{Determination of service level}

By service level we mean the extent of planned rate of the on-time delivered demand compared to the total demand. The accepted probability of shortage occurrence can be determined as a relation of the number of periods allowing shortages and the total number of periods analysed [4]. In the case where we allow two periods (e.g. weeks) uncovered by stocks for a complete one year period, the accepted probability of shortage occurrence can be defined as follows:

$$
S=\frac{p_{s} \cdot t}{T}=\frac{2 \cdot 7}{360}=0.0389
$$

where $S$ - accepted probability of shortage occurrence, $p_{s}$ - the number of a period stock-out, $t$ - the length of a given period, cycle length.

The service level can be defined by using the accepted probability of shortage occurrence:

$$
\mathrm{SL}=1-\frac{p_{s} \cdot t}{T}=0.9611,
$$

where SL is the service level.

From the standard normal distribution table we can get the value of $Z_{\mathrm{SL}}=1.765$ matching the probability value of the given 0.9611 . It means, we want to cover customer demands in approximately $96 \%$ of the periods. Another way to define the service level is to directly define the maximum allowed level of 
the probability of the shortage's occurrence (e.g. 0.02 $=2 \%$ ) and to find the matching $Z_{\mathrm{SL}}=2.33$ value. Irrespective of the definition of the service level, we apply the resulting value in a consistent way. $Z_{\mathrm{SL}}$ means the probability value of the SL service level from the standard normal distribution table [32, 33].

The density function detailed in Fig. 2 shows the probability of occurrence of actual quantities, which reflects that the frequency of occurrences is more typical around the expected value, while their probability decreases towards the two ends of the function. If we adjust the stocks only to the planned length of replenishment time and planned demand level, i.e. we do not keep a safety stock $\left(q_{n}=\mu\right)$, the probability of the occurrence of a shortage in case of demand with standard normal distribution will correspond to the probability of the non-occurrence of the shortage [2, 34]. The distribution function shows the probability of the coverage of demand fluctuations in relation to the changes of the stock level. The probability of the occurrence of the shortage decreases proportionally with the increase of the safety stocks; however, the complete safety can be guaranteed only by a stock with an infinite level. The introduction of the distribution function is justified by the fact that the function reflects well the probability of the occurrence of the stock shortage in connection with the stock level. The probability can be expressed as a risk, to which actual costs can be assigned. If we consider only the cost factors during the target settings, the optimal service level can be calculated by the given relation of stock-out costs and stock holding costs. The optimal service level is given at that inventory level, where the annual stock-out cost is equal to the annual stock holding cost [23].

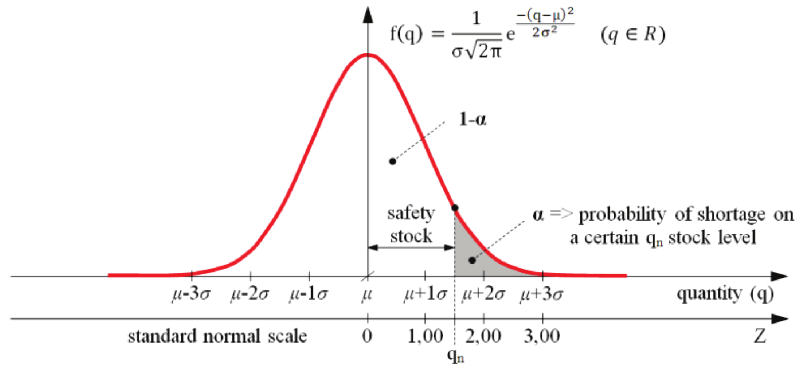

Fig. 2. Effect of the safety stock on the occurrence probability of the stock shortage.

\section{Variability in demand - the determination of accurate safety stock in the case of periodic review systems}

In a periodic inventory review system, the inventory on hand is reviewed at specific time intervals; e.g. every week or at the end of each business period. After the inventory in stock is defined, an order is placed for an amount that will fill the inventory up to a predetermined target level. The deterministic stock replenishment time and planned demand with constant intensity can be completed with the maximum extent of the demand fluctuation in two directions (Fig. 3) [23, 24]. Since the direction and extent of the deviation compared to the plan is stochastic, i.e. it cannot be exactly defined in advance; thus, the development of the actual utilisation demand and of stocks can be determined only with random variables. In case we only keep stocks to cover the planned demands, according to our stock management strategy, the increase in the actual utilisation demand compared to the plan would result in a drop to zero of the stocks before the date of receipt $[31,35]$.

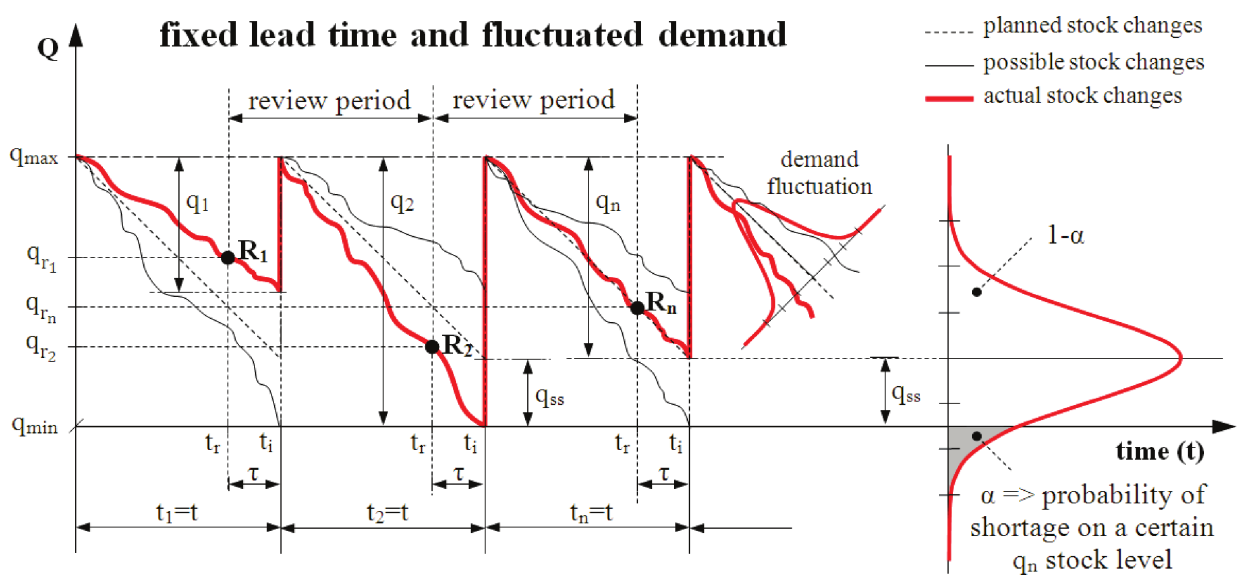

Fig. 3. Periodic review in case of stochastic change of demands. 
In the case of a periodic review, it is not only the next period's demand and the probable change of demands that need to be calculated during the placement of the order, but we also have to consider the extent of the demand changes expected for the remaining $\tau$ duration of the ordering period (Fig. 3).

As a first step, we must define the utilisation demand expected for the next period:

$$
d_{t}=t \cdot \bar{d}_{t},
$$

where $\bar{d}_{t}$ - the average level of demand during the given $t$-th period.

Subsequently, by the end of the period between the ordering point and order placement, thus, by the beginning of the next period, we must define the extent of the expected demand, which can be quantified similarly to the formula (11):

$$
d_{\tau}=\tau \cdot \bar{d}_{\tau},
$$

where $d_{\tau}$ - expected value of demand due within the stock replenishment period, $\tau$ - planned length of replenishment lead time, $\bar{d}_{\tau}$ - the average demand of the period between the ordering point and the period's end.

From the fluctuation of actual demands of past stockpiling periods, we can define the extent of demand fluctuation:

$$
\sigma_{d}=\sqrt{\frac{\sum_{i=1}^{n}\left(d_{i}-\bar{d}\right)^{2}}{n}},
$$

where $\sigma_{d}$ - the standard deviation of demand per unit time, $d_{i}$ - the demand belonging to the $t$-th period, $\bar{d}$ - the average level of demand of the examined period.

With full knowledge of demand variation characteristic to past periods, we can calculate the demand variation for the complete planning horizon. Thus, the variation of demand expected for the stock replenishment period and for the next stock-piling period:

$$
\sigma_{d_{(\tau+t)}}=\sigma_{d} \cdot \sqrt{\frac{\tau+t}{t_{\text {incr. }}}},
$$

where $\sigma_{d_{(\tau+t)}}$ - the standard deviation of demand during replenishment lead time and review period, $t_{\text {incr. }}$ - time increment used for calculating the standard deviation of demand.

In the case of predictable lead time and stochastic demand, the safety stock for a predefined service level is given:

$$
\begin{gathered}
q_{s s_{d}}=Z_{\mathrm{SL}} \cdot \sigma_{d_{(\tau+t)}}, \\
q_{s s_{d}}=Z_{\mathrm{SL}} \cdot \sigma_{d} \cdot \sqrt{\frac{\tau+t}{t_{\text {incr. }}}},
\end{gathered}
$$

where $q_{s s_{d}}$ - safety stock level created due to stochastic change of demands, $Z_{\mathrm{SL}}$ - value of standard deviation for desired service level.

\section{Variability in lead time - the determination of accurate safety stock in the case of continuous review systems}

In the case of continuous inventory review system, the inventory level is continuously monitored. Whenever the inventory on hand decreases to a predefined stock level, a new order is placed to replenish the stock. The ordered quantity is equal in each period that minimises the total inventory management costs. The stock replenishment time is not deterministic; it means the supply accuracy can fluctuate in two directions (Fig. 4).

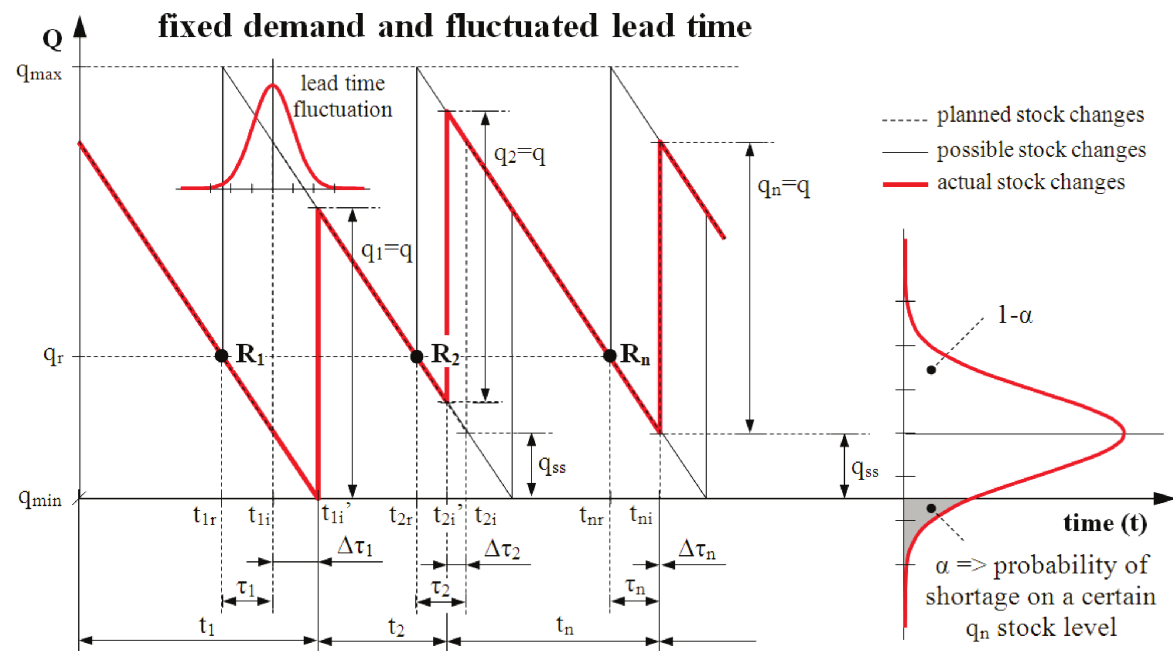

Fig. 4. Continuous stock review in case of stochastic replenishment period. 
Since the fluctuation of supply accuracy has a stochastic character, the development of the actual arrival date and of stocks can be determined only by random variables. In case we only keep stocks to cover the demands of the planned length of the period, the delayed receiving of the purchased parts compared to the planned arrival date would result in a drop to zero of the stocks before the date of receipt $[23,24]$.

During the quantification of the safety stocks, it is not enough to cover the utilisation demands expected for the remaining $\tau$ period of the ordering period; the temporal deviations during stock replenishment must be taken into account as well (Fig. 4) [4].

As a first step, we must define the length of stock replenishment time characteristic for the examined period, which can be derived from the stock replenishment times of the single periods:

$$
\bar{\tau}=\frac{\sum_{i=1}^{n} \tau_{i}}{n},
$$

where $\bar{\tau}$ - the average level of stock replenishment time during the examined period, $\tau_{i}$ - the stock replenishment time belonging to the $t$-th period.

To be able to define the relation between the supply accuracy and the necessary safety stock, we need to convert the stock replenishment time to the used quantity. Earlier, we measured the supply accuracy in time and not in quantity, so we must quantify the quantity used within the period between the planned stock replenishment time and the deviation compared to the deadline. By assuming a use of uniform $\bar{d}$ intensity, the used amount due within the planned average $\bar{\tau}$ stock replenishment:

$$
d_{\tau}=\bar{d} \cdot \bar{\tau},
$$

where $d_{\tau}$ - used amount due during the average stock replenishment.

The standard deviation of the average replenishment time can be calculated:

$$
\sigma_{\tau}=\sqrt{\frac{\sum_{i=1}^{n}\left(\tau_{i}-\tau\right)^{2}}{n}},
$$

where $\sigma_{\tau}$ - the standard deviation of the average replenishment time.

The demand during the average replenishment time fluctuation:

$$
d_{\sigma_{\bar{\tau}}}=\bar{d} \cdot \sigma_{\tau},
$$

where $d_{\sigma_{\bar{\tau}}}$ - the demand during the average replenishment time fluctuation in one single period.
In the case of predictable demand and stochastic replenishment time, the safety stock for a predefined service level is given:

$$
q_{s s_{\tau}}=Z_{\mathrm{SL}} \cdot d_{\sigma_{\bar{\tau}}}=Z_{\mathrm{SL}} \cdot \bar{d} \cdot \sigma_{\tau},
$$

where $q_{s s_{\tau}}$ - the safety stock level created due to stochastic replenishment time.

By the given service level, the ordering stock level is almost identical with the extent of the demand due to the length of the average stock replenishment time increased by the variation:

$$
q_{r}=\bar{d} \cdot \bar{\tau}+q_{s s_{\tau}}=d_{\sigma_{\bar{\tau}}}+Z_{\mathrm{SL}} \cdot d_{\sigma_{\bar{\tau}}} .
$$

\section{Variability both in lead time and demand at the same time}

It is not rare in practice that demands change stochastically at the same time, and that there is a deviation in the length of stock replenishment time compared to the planned one. Depending on whether there is a connection between the two phenomena, the safety stocks for the moderation of their effects must be calculated in a different way.

In case both lead time variability and demand fluctuation are normally distributed and are present at the same time, but independent of each other, the combined calculations result in a lower total safety stock than the sum of the two individual calculations. The necessary safety stock can be calculated using the following formula:

$$
\begin{aligned}
& q_{s s}=\sqrt{q_{s s_{d}}^{2}+q_{s s_{\tau}}{ }^{2}} \\
& =Z_{\mathrm{SL}} \cdot \sqrt{\bar{d}^{2} \cdot \sigma_{\tau}^{2}+\sigma_{d}^{2} \cdot \frac{\tau+t}{t_{\text {incr. }}}} .
\end{aligned}
$$

But if these two stochastic factors are not independent of each other, the sum of the two individual calculations gives the higher quantity of safety stock, than in the case lead time and demand fluctuation that are independent of from each other:

$$
\begin{gathered}
q_{s s}=q_{s s_{d}}+q_{s s_{\tau}}=Z_{\mathrm{SL}} \cdot \bar{d} \cdot \sigma_{\tau} \\
+Z_{\mathrm{SL}} \cdot \sigma_{d} \cdot \sqrt{\frac{\tau+t}{t_{\text {incr. }}}}=Z_{\mathrm{SL}} \cdot\left(d_{\sigma_{\bar{\tau}}}+\sigma_{d_{(\tau+t)}}\right) .
\end{gathered}
$$

\section{Conclusions}

The objective of the logistics management is to guarantee the stock level required for the adequate handling of production at the lowest possible level of costs and risks. For avoiding the effect of unexpected events, safety stocks as reserves can be held within the frame of stockpile management, but since their occurrence cannot be defined with great confidence and precision, their extent can be quantified with 
an estimating function too. By increasing the safety stock, the probability of the occurrence of the shortage decreases; however, the complete safety can be guaranteed only by an infinite stock level. The more stringent expectation we define towards the frequency of stock shortages in our stock management strategy, the higher the expenses will be for the avoidance of the stock shortage.

In practice, our aim is to define the accepted level of shortage occurrence, at which the customer satisfaction is guaranteed, and the total cost of the inventory management is optimal. Although there can be some influencing unpredictable factors, we can use the deterministic model as an approximation during the calculation of the order quantity. We also need to check the relation between the two factors, time and quantity, whether the lead time fluctuations and demand changes are present at the same time and depend on each other. After the selection of the appropriate variant, the optimal level of safety stock can be calculated by using the given formula.

In the case of stochastic demands, we can guarantee the achievement of the target level in two directions:

- we can decrease the uncertainty of the demand fluctuation with a more accurate forecast,

- we can increase the safety stocks to cover the fluctuating demands.

In the case of stochastic replenishment time, we can work on the achievement of the target level by two methods:

- with a stricter supplier qualification, we can reduce the uncertainty of supplies,

- we can increase the safety stocks to cover the fluctuating arrival date of purchased parts.

The management of utilisation demand changes and stock replenishment time changes of unpredictable extents urges the management of the production company to reach a compromise. The shortage of stocks can cause serious disturbances in the production supply and customer service, the costs of which are often unquantifiable. The avoidance of stock shortages is an important objective for every organisation; however, it would be possible only with the management of an infinite stock level due to the stochastic nature of demands and delivery performance. Stock management costs as well; thus, the definition of an optimum stock level is a task for an enterprise, where the combined costs of stock management and stock shortage show the lowest possible level.

A potential further step of the research would be to analyse the sensibility of the planned availability period and the impact of the cost factors on the total costs. The next research will focus on the analysis of the context of safety stock and the service level in the case of stockpile management model with planned shortages and lost demand.

The described study was carried out as part of the EFOP-3.6.1-16-00011 "Younger and Renewing University - Innovative Knowledge City - institutional development of the University of Miskolc aiming at intelligent specialisation" project implemented in the framework of the Szechenyi 2020 programme. The implementation of this project is supported by the European Union and co-financed by the European Social Fund.

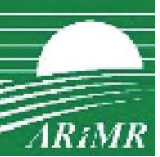

rth International Conference on Engineering, Project, and Production Management (EPPM2016) was co-organised by the Agency for Restructuring and Modernisation of Agriculture (Poland).

\section{References}

[1] Halászné S.E., Logistics - services, competitiveness [in Hungarian: Logisztika, szolgáltatások, versenyképesség], Magyar Világ Kiadó, Budapest, 1998.

[2] Kummer S., Grün O., Jammernegg W., Basics of purchasing, production, logistics [in German: Grundzüge der Beschaffung, Produktion und Logistik], Pearson Studium, München, 2009.

[3] Tersine R., Barman S., Lot size optimization with quantity and freight rate discounts, Logistics and Transportation Review, 27, 4, 319-332, 1991.

[4] Koltai T., Production Management [in Hungarian: Termelésmenedzsment], Typotex Kiadó, Budapest, 2009.

[5] Harris F.W., How many parts to make at once, Factory, The Magazine of Management, 10, 3, 135-136, 152, 1913.

[6] Ghare P.M., Scharder G.F., A model for an exponentially decaying inventory, Journal Industrial Engineering, 14, 238-243, 1963.

[7] Wagner H.M., Whitin T.M., Dynamic version of the economic lot size model, Management Science, 5, 1, 89-96, 1958.

[8] Porteus E.L., Optimal lot sizing, process quality improvement and setup cost reduction, Operations Research, 34, 1, 137-144, 1986.

[9] Park K.S., Inventory models with partial backorders, International Journal of Systems Science, 13, 13131317, 1982. 
[10] Hollier R.H., Mak, K.L., Inventory replenishment policies for deteriorating items in a declining market, International Journal of Production Research, 21, 813-826, 1983.

[11] Grubbström R.W., Erdem A., EOQ with backlogging derived without derivatives, International Journal of Production Economics, 59, 529-530, 1999.

[12] Deb M., Chaudhuri K.S., A note on the heuristic for replenishment of trended inventories considering shortages, Journal of Operational Research Society, 38, 459-463, 1987.

[13] Dave U., On a heuristic inventory-replenishment rule for items with a linearly increasing demand incorporating shortages, Journal of the Operational Research Society, 38, 459-463, 1989.

[14] Teng J.T., Yang H.L., Deterministic economic order quantity models with partial backlogging when demand and cost are fluctuating with time, Journal of the Operational Research Society, 55, 495-503, 2004 .

[15] Wee H.M., Yu J., Chen M.C., Optimal inventory model for items with imperfect quality and shortage backordering, Omega, 35, 7-11, 2007.

[16] Salameh M.K., Jaber M.Y., Economic production quantity model for items with imperfect quality, International Journal of Production Economics, 64, 59-64, 2000.

[17] Wee H.M., Yu J.C.P., Wang K.J., An integrated production inventory model for deteriorating items with imperfect quality and shortage backordering considerations, Lecture Notes in Computer Science, 3982, 885-897, 2006

[18] Eroglu A., Ozdemir G., An economic order quantity model with defective items and shortages, International Journal of Production Economics, 106, 544549, 2007.

[19] Vörös J., Production and service management [in Hungarian: Termelés- és szolgáltatásmenedzsment], Akadémia Kiadó, Budapest, 2010.

[20] Krampe H., Lucke H-J., Schenk M., Basics of logistics [in German: Grundlagen der Logistik], HussVerlag GmbH, München, 2012.

[21] Illés I., Companies' financial affairs [in Hungarian: Vállalkozások pénzügyi alapjai], SALDO Kiadó, Budapest, 1998.
[22] Szegedi Z., Prezenszki J., Logistics Management [in Hungarian: Logisztika-menedzsment], Kossuth Kiadó, Budapest, 2003.

[23] Vörös J., Production Management [in Hungarian: Termelésmenedzsment], Jannus Pannonius Kiadó, Pécs, 1991.

[24] Chopra S., Meindl P., Supply Chain Management Strategy, Planning, and Operation, Pearson Prentice-Hall Publishers, New York, 2007.

[25] Kulcsár B., Industrial logistics [in Hungarian: Ipari logisztika], LSI Oktatóközpont, Budapest, 1998.

[26] Vijayan T., Kumaran M., Fuzzy economic order time models with random demand, International Journal of Approximate Reasoning, 50, 3, 529-540, 2009.

[27] Jaynes E.T., Probability theory: The logic of science, Cambridge University Press, Cambridge, 2003.

[28] Huang B., Wu A., EOQ model with batch demand and planned backorders, Applied Mathematical Modelling, 40, 9-10, 5482-5496, 2016.

[29] Paknejad J., Nasri F., Affisco J.F., Yield improvement and yield variability reduction in an EOQ model with planned shortages and random yield, Computers \& Industrial Engineering, 88, 386-394, 2015.

[30] Cárdenas-Barrón L.E., A simple method to compute economic order quantities: Some observations, Applied Mathematical Modelling, 34, 1684-1688, 2010.

[31] Stock J.R., Lambert D.M., Strategic Logistics Management, McGraw-Hill Higher Education, Boston, 2001.

[32] Triola M.F., Elementary statistics, Pearson Education, New York, 2013.

[33] Kralikova R., Rusko M., Wessely E., Framework for Applying Six Sigma Methods within Environmental Management, in: Katalinic B. [Ed.], DAAAM International Scientific Book, Vienna, 545-552, 2012.

[34] Browder A., Mathematical analysis - an introduction, Springer, Berlin, 1996.

[35] Digiesi S., Mossa G., Mummolo G., A Sustainable Order Quantity Model under Uncertain Product Demand, IFAC Proceedings, 46, 9, 664-669, 2013. 